\title{
Determinan Perilaku Loyalitas Konsumen Indomaret Di Jakarta Barat
}

\author{
Debbie Aryani Tribudhi ${ }^{1}$, Soeharjoto ${ }^{2}$ \\ Fakultas ekonomi dan Bisnis, Universitas Trisakti \\ 1'debbie.aryani@trisakti.ac.id \\ 2ryoto16@yahoo.com
}

\begin{abstract}
ABSTRAK
Penelitian ini bertujuan untuk mengetahui perilaku loyalitas konsumen Indomaret di Jakarta Barat. Metode menggunakan Structural Equation Modeling (SEM), dengan variabel independen value equity, relationship equity, brand equity, positive emotions, negative emotions dan variabel dependennya loyalty intentions. Sampel sebanyak 255, dengan menggunakan teknik purposive sampling. Hasil penelitian yang diperoleh bahwa terdapat pengaruh yang positif dan signifikan antara brand equity terhadap loyalty intentions, relationship equity terhadap loyalty intentions, dan positive emotions terhadap loyalty intentions. Ada pengaruh yang negatif dan signifikan dari negative emotions terhadap loyalty intentions, sedangkan value equity terhadap loyalty intentions tidak berpengaruh. Dengan semakin banyak persaingan bisnis minimarket dan majunya digital teknologi, pihak Indomaret perlu melakukan inovasi dalam berbagai bidang dan melakukan kerjasama dengan pihak lain yang terkait, agar dapat tetap memiliki pembeli yang loyal.
\end{abstract}

Kata Kunci: loyalty intentions, value equity, brand equity, relationship equity, positive emotions, negative emotions.

\begin{abstract}
Purpose of this study is to know about Indomaret customer loyalty behavior at West Jakarta. Structural Equation Models (SEM) methods with value equity, relationship equity, brand equity, positive emotions, negative emotions as a independent variable and loyalty intentions as a dependent variable. Result from 225 sample with purposive sampling technique shown that there are positive and significant influence between brand equity to loyalty intentions, relationship equity to loyalty intentions, and positive emotions to loyalty intentions. There is negative and significant influence from negative emotions to loyalty intentions, but there's no influence between value equity to loyalty intentions. Increasingly competitive business at minimarket sector and advancement of digital technology, Indomaret should have an inovation at lots of area and have cooperation with another related parties to have a loyal customer.
\end{abstract}

Keywords : loyalty intentions, value equity, brand equity, relationship equity, positive emotions, negative emotions

Naskah diterima: 24 Juli 2019, direvisi: 23 Agustus 2019, diterbitkan: 16 September 2019

PENDAHULUAN

Bisnis ritel di Indonesia berkembang pesat, sehingga persaingannya semakin ketat. Ritel yang berkembang ini, dibedakan menjadi dua kelompok, yakni tradisional dan modern (www.aprindo.org). Adanya pertumbuhan ekonomi, teknologi, dan gaya hidup semakin membuat masyarakat menuntut kenyamanan dalam berbelanja, yang akhirnya terjadi pergeseran dari ritel tradisional ke modern.
Toserba Sarinah pada 1962 merupakan pemain pertama dalam bisnis ritel modern, kemudian pada awal 1990 SOGO sebagai peritel asing dari Jepang turut meramaikan bisnis ini, setelah itu dengan berdirinya Indomaret pada 1988 dan Alfamart pada 1999 perkembangan bisnis ritel semakin ramai. Apalagi untuk saat ini, semakin berkembangnya penggunaan uang elektronik di kalangan masyarakat, membuat peritel 
perlu melakukan inovasi guna meningkatkan peluang pasar yang ada (Tribudhi, 2019). Asosiasi pengusaha retail Indonesia (APRINDO) pada 2018, memiliki beberapa daftar nama minimarket dan jumlah gerai di Indonesia (Tabel 1).

Tabel 1. Minimarket yang tercatat di Asosiasi Pengusaha Retail Indonesia

\begin{tabular}{l|c}
\hline \multicolumn{1}{c}{ Nama } & Jumlah Gerai \\
\hline Alfamart & 15.526 \\
\hline Alfa Midi & 1.451 \\
\hline $\begin{array}{l}\text { Alfa Midi } \\
\text { Super }\end{array}$ & 13 \\
\hline Lawson & 37 \\
\hline Indomaret & 13.522 \\
\hline Circle K & 110 \\
\hline Family Mart & 100 \\
\hline Giant Express & 108 \\
\hline \multicolumn{2}{c}{ Sumber : Aprindo, 2018 }
\end{tabular}

Usaha ritel merupakan penjualan dengan menggunakan layanan dalam berbagai bentuk (Wee dan Ng-Tang, 2005). Peraturan Pemerintah No. 112 tahun 2007, menetapkan ritel modern sebagai toko modern dengan sistem pelayanan mandiri, menjual berbagai jenis barang secara eceran yang berbentuk minimarket, supermarket, department store, hypermarket ataupun grosir yang berbentuk perkulakan. Minimarket merupakan bentuk perdagangan ritel yang ditujukan untuk memenuhi kebutuhan masyarakat, sehingga berlokasi dekat dengan pemukiman penduduk (Jones dan Simons, 1990). Kondisi ini, membuat pesebaran minimarket sampai ke pelosok, agar dapat mencapai target pasarnya. Namun, guna meningkatkan kepercayaan masyarakat setempat yang akan berdampak pada peningkatan loyalitas, pihak minimarket perlu melakukan kerjasama dengan usaha mikro, kecil dan menengah (UMKM), (Soeharjoto, 2019). Dari semua merek minimarket yang tercatat di Aprindo, terdapat dua mini market yang masuk dalam top brand index produk retail modern, yakni Alfamart sebesar 52,9 persen dan Indomaret sebesar 41, 7 persen pada 2018.
Merek yang kuat belum tentu memilki jumlah gerai dan konsumen yang lebih banyak. Untuk itu, ritel modern perlu memiliki daya tarik agar konsumen akan datang lagi, yakni berupa kelengkapan kategori dan merek yang dijual, display yang menarik dan mudah dijangkau, ketersediaan barang dengan harga yang bersaing, serta pelayanan yang memuaskan (Andika dan Hati, 2017). Perlunya barang yang tersedia beragam, agar konsumen tetap setia dalam membeli produk, karena stiap konsumen mempunyai pihan tersendiri terhadap produk yang akan dibeli (Qin dan Prybutok, 2010). Adapun dampaknya, konsumen dalam sikap menentukan keputusan pembelian barang, berdasarkan pengalaman yang di dapatkan selama berbelanja (Lovelock dan Wirzt, 2016). Padahal, pelanggan loyal memiliki kecenderungan untuk melakukan switching cost dan menunjang strong word of mouth (Bowen dan Chen, 2001).

Pada era globalisasi, dengan semakin banyaknya berbagai peritel yang menjual berbagai produk yang sama, akan membuat persaingan semakin ketat, sehingga peritel perlu memiliki daya saing, agar dapat meningkatkan loyalitas pelanggan. Indomaret merupakan pelopor yang membuat bisnis ritel menjadi booming di Indonesia, disamping itu juga mememiliki pembeli yang loyal. Jakarta Barat merupakan daerah yang mempunyai jumlah penduduk terpadat, sehingga merupakan potensi pasar yang besar dalam mengembangkan bisnis ritel. Untuk itu, dilakukan penelitian determinan perilaku loyalitas konsumen Indomaret di Jakarta Barat.

\section{KAJIAN LITERATUR}

Konsumen yang melakukan belanja ritel, memiliki prinsip dasar dalam proses pengambilan keputusan, terutama dalam proses pengambilan keputusan yang terkait dengan pilihan terhadap ritel dan keputusan terhadap barangnya (Utami, 2010). Untuk itu, perusahaan perlu melakukan tindakan untuk menawarkan pada pihak lain sesuatu yang intangible dan tidak menghasilkan 
kepemilikan kepada pihak lain, berupa pelayanan (Kottler dan Keller, 2016). Aaker dan Keller (1990), mengungkapkan bahwa pelayanan yang baik akan meningkatkan nama perusahaan, sehingga akan berpengaruh positif pada respon konsumen terhadap barang dan jasa. Adapun hasilnya, akan berdampak pada sikap positif dari konsumen terhadap suatu objek, yang dapat membentuk komitmen berupa loyalitas (Mowen dan Minor, 1998).

Customer equity merupakan aliran pendapatan perusahaan yang diharapkan dari konsumen untuk jangka panjang, sehingga perlu dilakukan penyatuan manajemen customer value, brand dan relationship atau retention, agar dapat dijadikan dasar untuk kerangka strategi yang baru, guna membangun program pemasaran, yakni dengan berfokus pada konsumen, sehingga dapat lebih di pertanggungjawabkan dan diukur secara finansial (Abadi et.al., 2013). Agar hal tersebut dapat tercapai, perlu adanya loyalitas dari konsumen. Loyalty intention merupakan disposisi psikologis pelanggan terhadap suatu objek (Lin dan Liu, 2011). Hal ini, terjadi karena konsumen dalam suatu situasi merupakan cerminan sikap positif terhadap merek atau perusahaan, bahkan akan menimbulkan niat untuk membeli kembali suatu merek dan juga merekomendasikan merek tersebut kepada orang lain.

Loyalty intention dapat dipengaruhi oleh value equity, brand equity, relation equity, positive emotion, dan negative emotions (Razaq, et. al., 2017). Value equity menurut $\mathrm{Ou}$ et.al. (2017), merupakan penilaian obyektif pelanggan berdasarkan persepsi apa yang diserahkan untuk apa yang diterima tentang kegunaan barang atau layanan yang pelanggan konsumsi dan juga mencerminkan hasil perbandingan antara harapan dan kinerja perusahaan dimata pelanggan. Penelitian Razzaq et.al (2017), mengungkapkan bahwa brand equity akan dapat lebih tinggi, apabila pelanggan memiliki persepsi yang unik, kuat dan memiliki persepi yang diinginkan tentang merek tersebut. Merek juga akan memberikan nilai tambah dan bantuan dalam membedakan pesaing. Wu dan Batmunkh (2010), mengungkapkan bahwa merek yang kuat dapat menjadi payung untuk meluncurkan produk baru, sehingga merek yang kuat dapat menjadi sebuah pertahanan dalam situasi krisis, untuk melindungi dari persaingan industri. Ou et.al. (2017), menjelaskan bahwa relationship equity merupakan keseluruhan penilaian konsumen terhadap kualitas pada, saat melakukan interaksi dengan perusahaan. Atas dasar timbal balik tersebut, konsumen yang memahami hubungan yang baik dengan perusahaan, cenderung peduli terhadap kesejahteraan perusahaan dan akan menghindari keputusan yang dapat merusak perusahaan. Positive emotions merupakan keadaan yang menyenangkan sementara, dengan intensitas reaksi perilaku yang tenang atau tiba-tiba, dapat juga terjadi dengan tingkat kesadaran yang relatif tinggi dan orientasi, yang terdefinisi dengan baik (Andries, 2011). Cavanaugh et.al. (2015), mengungkapkan bahwa positive emotions berfungsi untuk memperluas cakupan attentional, cognitive, dan motivational guna memungkinkan adanya perspektif dan pengalaman baru. Andries (2011), menyatakan bahwa negative emotions adalah keadaan tidak menyenangkan yang sementara dengan intensitas variabel atas reaksi perilaku yang tenang atau bisa saja tiba-tiba dengan tingkat kesadaran yang relatif rendah. Negative emotions, terkait dengan kebutuhan yang tidak terpenuhi, hambatan untuk mencapai tujuan, sehingga mengakibatkan frustrasi, manajemen emosional yang tidak efisien yang disebabkan oleh kapasitas seseorang yang rendah untuk berhubungan dengan kebutuhan dan emosi mereka sendiri dan juga pengetahuan diri yang tidak mencukupi, pemikiran negatif serta cenderung menganggap segala sesuatu mengancam atau berbahaya, merugikan, peristiwa traumatis, hukuman dan berkendala (Andries, 2011).

Penelitian faktor-faktor yang mempengaruhi loyalitas konsumen sudah dilakukan beberapa peneliti. Razzaq et.al. (2017), membuktikan bahwa value equity berdampak positif terhadap loyalty intentions, yang artinya semakin tinggi persepsi akan meningkatkan manfaat atau kualitas yang diterima oleh konsumen, sehingga akan menciptakan niat 
konsumen untuk loyal terhadap perusahaan. Brand equity berdampak positif terhadap loyalty intentions, yang berarti bahwa merek yang kuat, inovatif dan sesuai dengan ekspektasi konsumen akan meningkatkan komitmen konsumen dengan perusahaan (Lin dan Liu, 2011). Relationshop equity akan berdampak positif terhadap loyalty intentions, yang menunjukkan bahwa konsumen akan merasakan adanya ikatan yang kuat dan perlakuan khusus yang diberikan perusahaan, sehingga akan membuat konsumen akan tetap bertahan dan terus melakukan pembelian ulang (Abadi et.al., 2013). Positive emotions akan memiliki dampak positif terhadap loyalty intentions, karena konsumen yang merasa senang atau puas terhadap produk atau layanan yang diberikan oleh perusahaan, memiliki efek yang konsisten, yaitu konsumen akan terus melakukan pembelian ulang atau menjadi loyal terhadap perusahaan, karena kualitasnya lebih dipercaya dibandingkan dengan mencoba kembali produk atau layanan perusahaan lain (Namkun dan Jang, 2010). Negative emotions akan berdampak negatif terhadap loyalty intentions dijelaskan oleh penelitian yang sebelumnya dilakukan oleh Razzaq et.al. (2017), yang mendukung bahwa konsumen dengan negative emotions akan memperlambat dan memperinci proses pengambilan keputusan, sehingga akan mengurangi niat konsumen yang sedang merasakan negative emotions ini untuk loyal terhadap perusahaan. Berdasarkan kajian literatur dan penelitian terdahulu, dapat dibuat kerangka pemikiran penelitian, yakni:

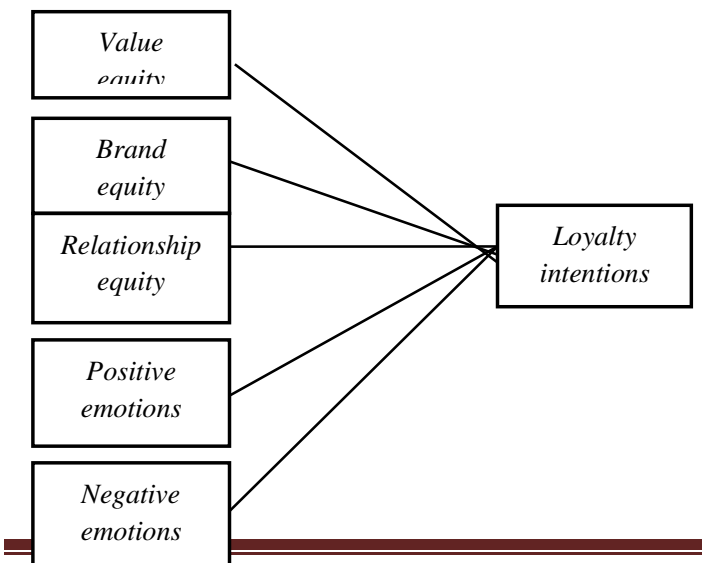

Gambar 1. Kerangka Pemikitan Penelitian

Hipotesis:

$\mathrm{H}_{1}$ : Value equity berpengaruh positif yang signifikan terhadap loyalty intentions,

$\mathrm{H}_{2}$ : Brand equity berpengaruh positif yang signifikan terhadap loyalty intentions.

$\mathrm{H}_{3}$ : Relationship equity berpengaruh positif yang signifikan terhadap loyalty intentions.

$\mathrm{H}_{4}$ : Positive emotions berpengaruh positif yang signifikan terhadap loyalty intentions.

$\mathrm{H}_{5}$ : Negative emotions berpengaruh negatif yang signifikan terhadap loyalty intentions.

\section{METODE PENELITIAN}

Penelitian ini untuk mengetahui determinan perilaku loyalitas konsumen Indomaret di Jakarta Barat. Metodenya menggunakan Structural Equation Modeling (SEM), dengan skala likert yang berskala 1-5. dan pengumpulan sampel non-probability sampling, yakni menggunakan teknik purposive sampling berdasarkan konsumen Indomaret yang pernah mengunjungi gerai Indomaret minimal 2 - 3 kali dalam sebulan, dengan jumlah sampel sebanyak 255. Variabel Independen yang digunakan value equity, relationship equity, brand equity, positive emotions dan negative emotions dan variabel dependennya loyalty intentions.

\section{PEMBAHASAN}

Hasil responden diperoleh sebanyak 263 jawaban, namun terdapat 8 jawaban responden yang tidak sesuai dengan kriteria, sehingga yang layak untuk masuk ke tahap pengujian adalah sebanyak 255 responden. Karakteristik responden yang berjenis kelamin perempuan sebanyak 157 responden (62 persen) dan sisanya laki-laki sebanyak 98 responden (38 persen). Paling banyak responden berumur 22 - 26 tahun, yakni sebanyak 136 responden (53 persen), berikutnya berumur 17 - 21 tahun sebanyak 112 responden (44 persen), dan yang berumur lebih dari 26 tahun sebanyak 7 responden (3 
persen). Dari 255 responden, yang terbanyak merupakan karyawan yakni sebanyak 181 responden (71 persen), berikutnya mahasiswa sebanyak 68 responden (27 persen), dan pelajar sebanyak 6 responden (2 persen). Sebanyak 38 responden (15 persen) mengunjungi gerai sebanyak $2-3$ kali dalam sebulan, 86 responden $(34$ persen $)$ mengunjungi gerai sebanyak 4-5 kali dalam sebulan, dan 131 responden (51 persen) mengunjungi gerai diatas 5 kali dalam sebulan.

Deskriptif variabel penelitian, dengan nilai rata-rata value equity adalah sebesar 3,83, sehingga menunjukkan bahwa Indomaret memiliki value equity yang baik dibenak para nasabahnya, seperti produk dan layanan yang ditawarkan adalah baik, fasilitas pendukung berada di tempat yang nyaman dan dapat ditemui dimana saja. Brand equity Indomaret memiliki merek yang kuat dan inovatif di benak para konsumennya. Konsumen merasakan adanya ikatan yang kuat dan juga manfaat yang baik dari Indomaret, serta adanya kecenderungan untuk merasa antusias pada saat mendengar informasi mengenai Indomaret, dengan nilai rata-rata relationship equity sebesar 3,61. Positive emotions responden mengungkapkan bahwa Indomaret memberikan pelayanan yang baik, sehingga konsumen merasakan perasaan positive emotions, seperti merasakan senang, antusias dan bahagia. Negative emotions responden yang pernah merasakan perasaan tidak menyenangkan mengenai produk dan pelayanan yang diberikan oleh Indomaret, seperti marah, sedih, kecewa, menyesal dan terganggu dengan pelayanan memiliki nilai rata-rata sebesar 1,95. Loyalty intentions konsumen yang berniat untuk menjadi konsumen loyal, dengan cara tetap berbelanja atau melakukan transaksi di Indomaret, ketika minimarket lain menawarkan keuntungan yang lebih baik, dengan nilai rata-rata sebesar 4,07 .

Teknik analisis yang digunakan dalam penelitian ini adalah structural equation model (SEM). Model persamaan SEM memungkinkan untuk melakukan pengujian suatu rangkaian hubungan yang relatif kompleks secara simultan, serta perpaduan dari dua analisis, yakni analisis faktor dan analisis regresi. Menurut Hair et.al. (2010), syarat dari pengujian hipotesis yang dilakukan adalah dengan membandingkan $\mathrm{p}$-value $(0,05)$ dengan ketentuan sebagai berikut:

a. Jika p-value $<0,05$ maka Ho ditolak

b. Jika $p$-value $\geq 0,05$ maka Ho gagal ditolak (diterima)

Pengujian kesesuaian model ini dilakukan dengan melihat kriteria pengukuran. Adapun hasil dari penelitian adalah:

Tabel 2. Hasil pengukuran kesesuaian (Goodness of Fit)

\begin{tabular}{l|c|c|c}
\hline Pengukuran & Nilai & Indikator & Kesimpulan \\
\hline Chi-Square & 227,382 & $\begin{array}{c}\text { Diharapkan } \\
\text { kecil }\end{array}$ & Poor Fit \\
\hline $\begin{array}{l}\text { P-Value } \\
\text { Chi-Square }\end{array}$ & 0,000 & $\geq 0,05$ & Poor Fit \\
\hline RMSEA & 0,51 & $\leq 0,08$ & Good Fit \\
\hline GFI & 0,918 & $\leq 0,90$ & Good Fit \\
\hline NFI & 0,916 & $\leq 0,90$ & Good Fit \\
\hline TLI & 0,955 & $\leq 0,90$ & Good Fit \\
\hline RFI & 0,895 & $\leq 0,90$ & $\begin{array}{c}\text { Marginal } \\
\text { Fit }\end{array}$ \\
\hline CFI & 0,964 & $\leq 0,90$ & Good Fit \\
\hline AGFI & 0,886 & $\leq 0,90$ & $\begin{array}{c}\text { Marginal } \\
\text { Fit }\end{array}$ \\
\hline CMIN/DF & 1,660 & $<2$ & Good Fit \\
\hline
\end{tabular}

Sumber: Hasil data olahan

Berdasarkan nilai goodness of fit dari tabel 2, maka model yang digunakan dalam penelitian ini memenuhi beberapa kriteria dari indikator yang ada. Dengan demikian model ini cukup layak untuk digunakan dalam penelitian. Adapun model yang terbentuk adalah: 


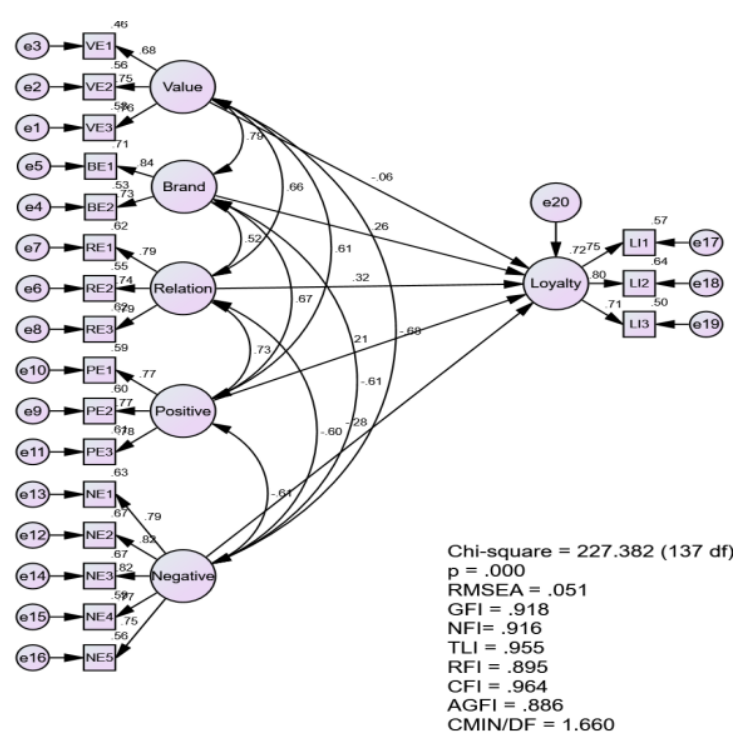

Gambar 2. Model Struktural

Skema penelitian yang terbentuk berdasarkan Structural Equation Modeling (SEM) adalah sebagai berikut :

Tabel 3. Hasil Pengujian Hipotesis

\begin{tabular}{c|c|c|c}
\hline $\begin{array}{c}\text { Hipotes } \\
\mathrm{a}\end{array}$ & Estimate & $\begin{array}{c}\mathrm{P}- \\
\text { value }\end{array}$ & Keputusan \\
\hline $\mathrm{Ha}_{1}$ & -0.065 & 0.0343 & $\mathrm{Ha}_{1}$ Ditolak \\
\hline $\mathrm{Ha}_{2}$ & 0.291 & 0.0355 & $\begin{array}{c}\mathrm{Ha} \\
\text { Diterima }\end{array}$ \\
\hline $\mathrm{Ha}_{3}$ & 0.313 & 0.004 & $\begin{array}{c}\mathrm{Ha} \\
\text { Diterima }\end{array}$ \\
\hline $\mathrm{Ha}_{4}$ & 0.210 & 0.0465 & $\begin{array}{c}\mathrm{Ha} \\
\text { Diterima }\end{array}$ \\
\hline $\mathrm{Ha}_{5}$ & -0.251 & 0.0005 & $\begin{array}{c}\mathrm{Ha} \\
\text { Diterima }\end{array}$ \\
\hline
\end{tabular}

Sumber : Hasil data olahan.

Dari hasil uji hipotesis dapat diketahui bahwa nilai signifikansi pengaruh value equity terhadap loyalty intentions sebesar $0,686 / 2=0,343>0,05$, dan nilai pengaruh value equity terhadap loyalty intentions sebesar 0,065 , yang artinya value equity tidak signifikan terhadap loyalty intentions. Nilai signifikansi pengaruh brand equity terhadap loyalty intentions sebesar $0,071 / 2=0,0355<$ 0,05 dengan nilai pengaruh brand equity terhadap loyalty intentions sebesar 0,291, yang berarti brand equity akan berpengaruh positif dan signifikan terhadap loyalty intentions. Nilai signifikansi pengaruh relationship equity terhadap loyalty intentions sebesar $0,008 / 2=0,004<0,05$, dengan nilai pengaruh sebesar 0,313 , yang berarti relationship equity berpengaruh positif dan signifikan terhadap loyalty intentions. Nilai signifikansi pengaruh positive emotions terhadap loyalty intentions sebesar $0,093 / 2=0,0465<0,05$, dengan nilai pengaruh sebesar 0,210, yang artinya positive emotions berpengaruh positif dan signifikan terhadap loyalty intentions. Nilai signifikansi pengaruh negative emotions terhadap loyalty intentions sebesar $0,001 / 2=0,0005<0,05$, dengan nilai pengaruh sebesar minus 0,251 , yang berarti negative emotions berpengaruh negatif dan signifikan terhadap loyalty intentions.

Value equity tidak berdampak positif yang signifikan terhadap loyalty intentions. Hal ini menunjukan bahwa tingginya value equity terhadap Indomaret, yang ada dalam benak konsumen, tidak dapat menjamin konsumen tersebut akan loyal terhadap Indomaret, sehingga tidak berdampak postif. Brand equity dapat meningkatkan loyalty intentions konsumen terhadap perusahaan. Artinya, konsumen lebih mempercayai atau menggunakan merek yang kuat dan inovatif untuk dikonsumsi, dikarenakan merek tersebut lebih dipercaya dan telah diketahui reputasinya dikalangan masyarakat, sehingga konsumen tidak akan ragu untuk menjadi konsumen yang loyal. Hasil penelitian yang dilakukan oleh Vogel et.al. (2008), memiliki hasil serupa, yang menunjukkan terdapat pengaruh positif yang signifikan dari brand equity terhadap loyalty intentions. Adanya ikatan dalam hubungan antara konsumen dengan perusahaan, sangatlah penting bagi tingkat loyalitas kepada perusahaan. Ketika konsumen telah merasa adanya ikatan yang kuat dan memperoleh manfaat dari perusahaan serta akan merasa antusias jika mendengar informasi mengenai perusahaan, sehingga konsumen akan meningkatkan niat 
konsumen untuk tetap menggunakan jasa perusahaan tersebut. Hasil penelitian ini serupa dengan hasil penelitian yang dilakukan oleh Ramaseshan et.al. (2013), dimana dalam penelitiannya relationship equity berdampak positif terhadap loyalty intentions. Maka dari itu, dapat disimpulkan dengan semakin meningkatnya relationship equity yang dirasakan oleh konsumen, juga akan meningkat loyalty intentions, yang akan ditimbulkan oleh konsumen. Positive emotions dapat meningkatkan loyalty intentions konsumen terhadap perusahaan. Artinya, konsumen yang merasa bahagia, senang dan antusias ketika menggunakan fasilitas dari Indomaret, serta akan mempercayai perusahaan tersebut dan akan memiliki niat untuk menjadi konsumen yang loyal. Negative emotions dapat menurunkan tingkat loyalty intentions konsumen terhadap perusahaan. Dengan demikian, konsumen yang merasa kesal, kecewa, terganggu akan kualitas produk atau layanan yang diberikan oleh perusahaan akan membuat konsumen menjadi tidak menyukai perusahaan itu lagi dan akan mengurangi niat konsumen tersebut untuk menjadi loyal.

\section{PENUTUP}

Berdasarkan hasil penelitian diperoleh hasil bahwa terdapat pengaruh yang positif dan signifikan antara brand equity terhadap loyalty intentions, relationship equity terhadap loyalty intentions, dan positive emotions terhadap loyalty intentions. Ada pengaruh yang negatif dan signifikan dari negative emotions terhadap loyalty intentions, sedangkan value equity terhadap loyalty intentions tidak berpengaruh. Indomaret untuk meningkatkan loyalitas konsumen, agar dapat bersaing di bisnis ritel, perlu meningkatkan kualitas produk, fasilitas, layanan, komunikatif, inovatif dan melakukan kerjasama dengan pihak lain yang terkait.

\section{REFERENSI}

Andika, Heru dan Shinta Wahyu Hati. 2017. Analisis Perbandingan Kepuasan Pelanggan Antara Mini Market Indomaret Dengan Alfamart di Kota Batam. Jurnal Akuntansi, Ekonomi dan Manajemen Bisnis. Vol. 6(2).
Abadi, H. R. D., N. Kabiry and M. H. Forghani. 2013. Analyzing the Effect of customer Equity on Satisfaction. International Journal of Academic Research in Business and Social Sciences. Vol. 3(5).

Andries, Alina Maria. 2011. Positive and Negative Emotions Within The Organizational Context. Global Journals of Human Social Science. Vol. 11(1).

Aaker, David A. dan Kevin Lane Keller. 1990. Consumer Evaluation of Barand Extensions. Journal of Marketing. Vol. 54(1).

Bowen, J.T. and S. Chen. 2001. The Relationship Between Customer Loyalty and Costumer Satisfaction. International Journal of Contemporary Hospitality Management. No. 13(4/5).

Cavanaugh, Lisa A., James R. Bettman and Mary Frances Luce. 2015. Feeling Love and Doing More for Distant Others: Specific Positive Emotions Differentially Affect Prosocial Consumption. Journal of Marketing Research. Vol. 52(5).

Hair, J.F., W.C. Black, B.J. Babin and R.E. Anderson. 2010. Multivariate Data Analysis. Pearson Prentice Hall. New Jersey.

Jones, Ken and Jim Simons. 1990. Location Location Location Analyzing the Retail Environment. Nelson. Canada.

Kotler, Philip and Kevin Keller. 2016. Marketing Management. Prentice Hall. US.

Lovelock, Christopher and Jochen Wirtz. 2016. Service Marketing: People, Technology, Strategy. World Scientific Publishing. US. 
Lin, Yu-Li and Hsiu-Wen Liu. 2011. Service Worker Role in Encouraging Customer Equity: Dyadic Analysis. INFORMS Marketing Science Conference. June 911. Houston. USA.

Mowen and Minor. 1998. Loyalty is a Simple. Journal of Service Research. Vol. 3(6).

Namkung, Y. And Soo Cheong (Shawn) Jang. 2010. Effect of Perceived Service Fairness on Emotions, and Behavioral Intentions in Restaurants. European Journal of Marketing. Vol. 44(9/10).

Ou, Yi-Chun., Peter C. Verhoef and Thorsten Wiesel Verhoef. 2017), The Effect of Customer Equity Drivers on Loyalty Across Service Industries and Firms. Journal of the Academy of Marketing Science. Vol. 45(3).

Qin, H and V.R. Prybutok. 2010. Service Quality, Customer Satisfaction, and Behavioral Intention in Fast Food Restaurant. International Journal of Quality and Services Sciences. Vol. 1(1).

Razzaq, Zohaib., Salman Yousaf and Zhao Hong. 2017. The Moderating Impact of Emotions On Customer Equity Drivers And Loyalty Intentions Evidence Of Within Sector Differences. Asia Pacific Journal of Marketing and Logistics. Vol. 29(2).

Ramaseshan, B., F. K. Rabbanee and L. T. H. Hui. 2013. Effects of customer equity drivers on customer loyalty in B2B context. Journal of Business and Industrial Marketing. Vol. 28 (4).

Soeharjoto. 2019. Determinasi penyaluran kredit umkm di provinsi Kalimantan timur. FORUM EKONOMI. Vol. 21(2).
Tribudhi, Debbie Aryani dan Soeharjoto. 2019. Determinasi transaksi dengan menggunakan uang elektronik di Indonesia. KINERJA. Vol. 16(1).

Utami, C. W. 2010. Manajemen Ritel. Salemba Empat, Jakarta.

Vogel, Verena, Heiner Evanschitzky and B. Ramaseshan. 2008. Journal of Marketing. Vol. 72(6).

Wee, Lyndia and Cyntia Ng-Tang. 2005. Managing the Brick-and-Mortar Retail Stores. Bhuana Ilmu Populer. Jakarta.

$\mathrm{Wu}, \mathrm{T}$. F. and M. U. Batmunkh. 2010. Exploring The Relationship Between Customer Equity and Satisfaction: An Empirical Study of Mongolian Gas Station Channels. International Journal of Trade, Economics and Finance. Vol. 1 (2).

www.aprindo.org

\section{BIODATA PENULIS}

Debbie Aryani Tribudhi, SE, MM, lahir di Jakarta pada 1973 dan sebagai dosen Fakultas Ekonomi dan Bisnis, Universitas Trisakti. Karya yang dihasilkan Determinasi transaksi dengan menggunakan uang elektronik di Indonesia (Jurnal KINERJA).

Soeharjoto, SE, MSi, lahir di Prabumulih pada 1970 dan aktif sebagai dosen Fakultas Ekonomi dan Bisnis, Universitas Trisakti. Beberapa karya yang dihasilkan pada jurnal ilmiah, dengan Scopus ID: 57203802994 dan SINTA ID : 5988889. 